\title{
EKSISTENSI MAMANDA DALAM MASYARAKAT KALIMANTAN SELATAN
}

\section{Endang Sulistyowati ${ }^{1}$}

\section{Program Studi Pendidikan Bahasa dan Sastra Indonesia STKIP PGRI Banjarmasin endangsulistyowati65@gmail.com (08125109840)}

\begin{abstract}
ABSTRAK
Mamanda merupakan salah satu kesenian (pertunjukan) daerah Kalimantan Selatan. Mamanda mulai dikenal pada awal abad kedua puluh dengan nama Badamuluk. Mamanda dimainkan dalam bentuk arena sentral, posisi para pemain saat berlakon berada di tengah-tengah penonton. Ada dua aliran yang dikenal pada mamanda, yaitu mamanda Batang Banyu dan Mamanda Tubau. Ciriciri mamanda dapat dilihat baik dari segi bahasa, simbol, humor, estetika, dan tipe cerita. Tahapan-tahapan mamanda meliputi lagu (lagu Banjar), ladon atau konon, perkenalan panganan dan pangiwa, sidang kerajaan, dan babujukan. Sejauh yang dapat dicatat, mamanda di Kalimantan Selatan sudah eksis sejak tahun lima puluhan hingga sekarang. Hal tersebut dapat diketahui baik dari munculnya beberapa nama seniman (pelakon) mamanda maupun munculnya beberapa teater, sanggar, atau group mamanda di Kalimantan Selatan. Dalam rangka mengembangkan mamanda di Kalimnatan Selatan, agar mamanda semakin eksis, diharapkan adanya peran dari beberapa pihak, baik yang berkaitan dengan pemerintah, lembaga pendidikan, seniman, maupun masyarakat.
\end{abstract}

Kata Kunci: eksistensi, mamanda, Kalimantan Selatan

\section{PENDAHULUAN}

\section{A. Asal-usul Mamanda}

Mamanda merupakan salah satu kesenian (pertunjukan) daerah Kalimantan Selatan. Mamanda mulai dikenal pada awal abad kedua puluh dengan nama Badamuluk. Kata Badamuluk diambil berdasarkan cerita yang dipergunakan saat itu, berupa cerita yang berasal dari Syair Abdul Muluk. Ba-Abdul Muluk berarti melakonkan Abdul Muluk. Perkataan tersebut kemudian berubah menjadi Badamuluk. Nama Mamanda didasarkan atas kebiasaan raja memanggil Wazir atau Mangkubumi dengan perkataan "pamanda" atau "mamanda." Akhirnya, perkataan tersebutlah yang dipergunakan sampai sekarang. Mamanda mengandung tiga unsur seni, yaitu gerak (lakon), nyanyi, dan tari. Gerak (lakon) dengan monolog dan dialog merupakan unsur utama yang membangun adanya mamanda keseluruhan. Nyanyi dan tari merupakan unsur pelengkap di samping lawak yang juga merupakan bagian dari mamanda.

Pertunjukan mamanda (biasanya) dilakukan pada malam hari misalnya untuk merayakan perkawinan, acara keramaian kampung, atau untuk hiburan 
biasa. Tempat pertunjukan berbentuk arena sentral, empat persegi panjang dengan perlengkapan yang sangat sederhana. Untuk penerangan, dipergunakan beberapa lampu stormking dan di tempat raja bersemayam diletakkan sebuah meja kayu. Sebagai musik penggiring di samping arena terdapat seperangkat peralatan orkes melayu, sebuah kendang yang dinamakan "babun" dan gong. Babun berfungsi sebagai genderang irama tertentu disertai pukulan gong, yang selalu diiringi dengan suara "gaduk." Setiap pelaku yang keluar dari Kurung Sari selalu diiringi dengan suara gaduk. "Kurung Sari" adalah kamar ganti pakaian yang didirikan di samping arena, bertentangan dengan letak meja tempat raja bersemayam. Pelaku mamanda biasanya terdiri dari tiga golongan, yaitu raja beserta bawahannya, orang miskin, dan komplotan perampok. Pembagian ini memberikan gambaran tiga lapisan masyarakat, yaitu kaum bangsawan, rakyat jelata, dan para penjahat yang biasa melakukan kekacauan.

Cerita mamanda berkisar pada sebuah kerajaan yang digambarkan sebagai negara kaya raya tidak kurang suatu apa jua pun, dan tak terkalahkan, berkat pimpinan rajanya yang bijaksana. Setiap perkataan bawahan selalu berisi sanjung puji terhadap raja. Walaupun demikian, masih ada golongan rakyat jelata yang hidupnya selalu kekurangan, tetapi tabah dan bersifat jujur. Di samping itu, ada lagi satu golongan pengacau negara dalam bentuk komplotan perampok. Gerombolan inilah yang menyerang kerajaan. Pada akhirnya si miskin datang membela negara dari kekuasaan perampok, dengan ketangkasan dan keberaniaanya berhasil menyelamatkan negara. Untuk jasanya itu, dia dikaruniai harta, pangkat, atau dikawinkan dengan putri raja (Sunarti, 1978:230-232).

Mamanda dimainkan dalam bentuk arena sentral, posisi para pemain saat berlakon berada di tengah-tengah penonton. Lakon yang dibawakan diambil berdasarkan cerita rakyat, hikayat, sejarah, bahkan juga cerita kekinian (karangan baru). Mamanda di dalam perkembangannya mengalami berbagai proses sampai akhirnya menumbuhkan aliran baru. Ada dua aliran yang dikenal pada mamanda, yaitu mamanda Batang Banyu dan Mamanda Tubau. Mamanda Batang Banyu yang berasal dari daerah Margasari sering pula disebut Mamanda Periuk.

Mamanda Tubau merupakan perkembangan baru dari seni mamanda yang pengaruhnya cukup kuat dan terkenal di daerah asalnya yaitu Desa Tubau Kabupaten Hulu Sungai Tengah (HST). Mamanda Tubau dewasa ini berkembang dengan pesat di seluruh pelosok Kalimantan Selatan, tetapi tidak lagi disebut dengan istilah Mamanda Tubau. Strukturnya menganut suatu sistem yang sudah dibakukan, yaitu dimulai dengan ladon atau kanon, siding kerajaan, kemudian cerita (http://www.kompasiana.com/husaini.angkinang/ kesenian-mamanda- yangmasih-eksis-di-hss_551fc93a81331151019dfd21).

\section{B. Ciri-ciri Mamanda}

Ciri-ciri mamanda dapat dilihat baik dari segi bahasa, simbol, humor, estetika, maupun tipe cerita (Jarkasi, 2002:31-74). Dari segi bahasa, pada umumnya bahasa yang digunakan pada mamanda yaitu bahasa Melayu Banjar. Dengan menggunakan bahasa Banjar, pelakon mamanda lebih mudah berkomunikasi, baik kepada sesama pelakon maupun penonton. Pelakon juga akan lebih mudah memahami dan mengungkapkan humor serta unsur-unsur budaya dalam kisahan mamanda yang disuguhkan kepada penonton. 
Seiring dengan perkembangan zaman, pelakon mamanda juga menyadari bahwa penonton mamanda tidak hanya terdiri dari masyakarat Banjar, tetapi juga berasal dari masyarakat lain yang ada di Kalimantan Selatan khususnya, seperti masyarakat dari Jawa, Sunda, Madura, Bugis, Batak, serta Minang. Untuk itu, bahasa memanda tidak hanya bahasa Melayu Banjar, tetapi juga mengalami perkembangan. Bahasa mamanda juga menggunakan bahasa Indonesia dengan logat Banjar atau menggunakan bahasa Banjar dengan campuran bahasa Indonesia. Pada dialog tertentu pelakon mamanda kadang-kadang melakukan alih kode atau berganti bahasa dari (kalimat-kalimat) bahasa Banjar ke bahasa etnik tertentu. Alih kode tersebut digunakan selain memudahkan dalam berkomunikasi juga sebagai penghormatan kepada penonton yang bukan berasal dari Banjar agar ikut memahami kisahan mamanda.

Dilihat dari segi simbol, mamanda sebagai sebuah bentuk kesenian rakyat tidak hanya menyajikan ekspresi yang bersifat permainan, tetapi juga menghantar simbol-simbol kehidupan manusia dalam simulasi makhluk berbudaya. Dalam permainan mamanda telah direkontruksi rasa dan idealisme yang berisi wawasan batin dan wawasan perilaku orang perorang, baik sebagai rakyat biasa maupun sebagai kelompok penguasa. Simbol-simbol yang tersaji dalam mamanda memberikan rangsangan terhadap pengalaman imajinatif terhadap kisah-kisah yang disajikan. Beberapa simbolisme mamanda selalu dikaitkan dengan komunikasi budaya. Kuatnya tradisi tersebut dapat dilihat dari struktur pargelaran dari babakan ladon, gambaran kerajaan (masuknya pengawal), memuja-muja kerajaan, sidang kerajaan, konflik, klimaks, dan babujukan (selesaian).

Dilihat dari segi humor, dalam mamanda pada fase-fase awal lahirnya mamanda, unsur yang berisi nilai humor (lucu) hanya dilakonkan oleh Hadam dan Inang. Dua pelakon tersebut berperan sebagai pesuruh istana sekaligus pengasuh anak raja. Pelakon lain tidak diperkenankan bersikap lucu, sebab mereka tetap harus memelihara fungsinya sebagai staf kerajaan. Lebih-lebih pada struktur mamanda yang bersifat tradisi, alur cerita yang mencekam harus tetap dipertahankan. Oleh karena itu, unsur-unsur yang dapat menimbulkan gelak tawa orang hanya dilakukan oleh Hadam dan Inang.

Meskipun demikian, modus kisahan semacam itu lama kelamaan semakin tersisih dengan hiburan lain (kesenian modern) yang lebih mampu menciptakan keterhiburan bagi masyarakat (penonton). Oleh karena itu, kondisi semacam itu membuat pelakon memanda melakukan perubahan dengan (mencoba) menggarap kisahan yang berisi humor, termasuk memasukkan lagu-lagu dangdut (terutama) di sela-sela pertunjukan mamanda. Modus semacam itu ternyata (cukup) menambatkan kembali emosi penonton terhadap pertunjukan mamanda. Humor pada mamanda tersebut misalnya humor yang berkenaan dengan bahasa, tingkah laku, dan pergunjingan. Humor bahasa yaitu kelucuan-kelucuan yang disebabkan oleh penuturan kalimat-kalimat atau ungkapan-ungkapan bahasa yang dilakukan oleh pelakon mamanda. Humor tingkah laku yaitu perilaku atau sikap pelakon mamanda yang sengaja dibuat-buat untuk menimbulkan kelucuan. Humor pergunjingan yaitu humor yang dalam bahasa Banjar disebut dengan istilah bahuhulutan (saling mengejek), dalam mamanda bahannya yang paling banyak diambil sebagai inspirasi humor adalah ciri pribadi atau predikat yang dimiliki oleh seseorang (termasuk pelakon) seperti bertubuh besar, bertubuh pendek, kerdil, atau kurus tinggi. 
Dilihat dari segi estetika, mamanda adalah sebuah model interaksi manusia dengan segala kedudukan dan fungsinya serta dikemas dalam ekspresi gerak tari, lagu dan tetabuhan, simbol yang disimbiosekan dengan nilai kearifan lokal (kultur Banjar). Estetika lain dari gambaran mamanda adalah struktur yang bergerak mengikuti alur cerita yang bermula dari ladon, sidang kerajaan, jalan cerita, dan babujukan (antiklimaks). Struktur tersebut menyaran pada model tatanan bermasyarkat dalam hidup bernegara (berkerajaan) serta ideasi citra kepemimpinan oleh penguasa. Ada dua hal yang perlu dikedepankan dalam hukum pertunjukan mamanda, yaitu sidang kerajaan dan alur cerita yang selalu happy ending.

Dilihat dari segi tipe cerita, sumber cerita pada mamanda cukup banyak yang bersumber dari cerita seperti kisah seribu satu malam, cerita rakyat, syair, dan hikayat yang dipandang memiliki etika yang dapat diambil sebagai inspirasi untuk menata perilaku masyarakat. Selain itu bisa pula cerita bersumber dari kehidupan, karena mamanda dalam ceritanya merupakan aktivitas kebudayaan rakyat yang mereflesikan kehidupan sehari-hari, baik yang berkenaan dengan sejarah, romantis, kritik sosial, maupun yang bersifat penerangan (pesan-pesan pembangunan).

\section{Pertunjukan Mamanda}

Mamanda biasanya dipertunjukkan pada malam hari untuk menghibur masyarakat. Pertunjukan mamanda pada umunya disajikan secara sederhana dan mudah dilaksanakan oleh rakyat. Adapun tahapan-tahapan mamanda meliputi lagu (lagu Banjar), ladon atau konon, perkenalan panganan dan pangiwa, sidang kerajaan, dan babujukan (Jarkasi, 2002:220-224). Beberapa tahapan mamanda tersebut, secara ringkas dapat dikemukakan sebagai berikut:

\section{Lagu (Lagu Banjar)}

Penyajian lagu-lagu Banjar biasanya diiringi dengan musik panting, yaitu instrumen musik petik bersenar tiga. Untuk mengiringi lagu-lagu Banjar, panting biasanya dilengkapi dengan alat musik seperti biola, babon, gong, dan terkadang seruling. Sajian lagu-lagu tersebut dimaksudkan untuk mengajak penonton agar segera mendekat ke arena pertunjukan mamanda. Lagu yang disajikan biasanya yang berirama romantis. Dahulu pernah juga disajikan musik dangdut. Akan tetapi sekarang (cukup) hanya dengan musik panting.

\section{Ladon atau Konon}

Jika penonton sudah berkumpul mengelilingi arena penonton, sajian lagulagu diakhiri, kemudian dilanjutkan dengan baladon. Ladon atau sering pula disebut konon adalah tahapan penyampaian judul kisah yang akan dimainkan. Tahapan ladon diawali dengan sajian tarian, yang disebut tarian ladon. Bermain ladon dapat dilakukan tiga sampai tujuh orang penari atau dalanm jumlah ganjil seperti tiga orang, lima orang, atau tujuh orang. Satu orang di antara peladon biasanya menjadi pimpinan ladon, yang secara teatral menjadi penyelia, mempersilakan para peladon membawakan tarian ladon secara bergantian, yang seolah-olah diadakan pertandingan tari ladon.

Penyampaian ladon dapat dilakukan dalam durasi lima sampai lima belas menit. Durasi tersebut disesuaikan dengan durasi pertunjukan mamanda secara 
keseluruhan. Jika pertunjukan mamanda mencapai tiga sampai empat jam, maka ladon dapat dimainkan dalam durasi sampai lima belas menit. Namun, pertunjukan mamanda dalam durasi panjang sudah jarang dilaksanakan. Dewasa ini, paling banter pertunjukan mamanda dilaksanakan dalam durasi satu setengah sampai dua jam. Oleh karena itu, penyampaian ladon hanya dilakukan dalam durasi (kurang kebih) lima menit. Jika penyampaian tari sudah berakhir, pimpinan ladon segara memberitahukan kepada penonton tentang judul kisah mamanda yang dibawakan.

\section{Perkenalan Panganan dan Pangiwa}

Pertunjukan mamanda (dimulai) dengan masuknya dua orang pengawal kerajaan yang disebut dengan panganan dan pangiwa atau harapan pertama dan harapan kedua. Disebut panganan dan pangiwa, karena kedua hulu balang ini selalu berdiri di pintu gerbang kerajaan secara berdampingan, ada yang di sebelah kanan dan ada yang di sebelah kiwa (kiri). Adapun penyebutan harapan pertama dan harapan kedua, karena kedua hulu balang ini sekaligus merupakan ujung tombak atau harapan untuk menjaga dan mempertahankan kewibawaan kerajaan dari masuknya pengaruh-pengaruh dan ancaman, baik dari dalam maupun dari luar kerajaan. Kedua pengawal tersebut kemudian memperkenalkan nama dan jabatan sekaligus kehebatan ilmu dan keberanian masing-masing. Setelah itu, mereka pun menyiapkan sesuatu di ruang kerajaan, sebab sebentar lagi raja akan memasuki balai persidangan.

\section{Sidang Kerajaan}

Raja beserta seluruh staf kerajaan yang terdiri dari mangkubumi, wajir, kepala pertanda, perdana menteri memasuki balai persidangan, yang kemudian dilanjutkan dengan mendengarkan laporan dari staf kerajaan. Biasanya pada tahap ini seluruh staf kerajaan dipersilakan menyampaikan masalah atau sesuatu yang menggegerkan masyarakat. Raja kemudian melakukan pembahasan berkaitan dengan masalah kerajaan, kemudian mengambil sikap dan tindakan apa yang akan diambil berkaitan dengan masalah tersebut.

Secara ideal, sidang kerajaan dalam kisah-kisah mamanda dilakukan secara demokratis. Semua tokoh dimintai pendapat. Bahkan hadam dan inang, serta orang kampung pun terkadang sengaja dipanggil untuk dimintai pendapat berkenaan dengan masalah yang dibahas. Sebelum raja mengambil keputusan, ia pun masih meminta nasihat kepada wajir sebagai penasihat kerajaan. Rangkaian cerita dimulai sejak diketahuinya masalah dalam sidang kerajaan, kemudian dilanjutkan dengan babakan-babakan berikutnya seperti pertentangan, konfliks, klimaks, antiklimaks, dan penyelesaian.

\section{Babujukan}

Babajukan adalah adengan membujuk atau merayu gadis atau puteri raja oleh seorang pemuda kesatria. Adengan ini merupakan tahap akhir dari pertunjukan mamanda yang berisi antiklimaks kisah yang dibawakan. Pemuda kesatria atau puteri dan gadis menari bersama masyarakat, terkadang penonton juga diajak menari. Tarian untuk penonton atau masyarakat biasanya tari gandut. Untuk dapat menari di tengah-tengah arena, biasanya penyelenggara pertunjukan menyiapkan sasanggan, yaitu tempayan dari kuningan (perunggu). Tempat tersebut diisi oleh penari lain, yang secara bergantian ikut dalam keramaian. 


\section{PEMBAHASAN}

\section{A. Eksistensi Mamanda dalam Masyarakat Kalimantan Selatan}

Sejauh yang dapat dicatat, mamanda di Kalimantan Selatan sudah eksis sejak tahun lima puluhan. Hal tersebut dapat diketahui sejak tahun lima puluhan sudah dapat dikenal berberapa seniman mamanda seperti Laut, Basirun, Ramli, Tukacil, Katuyung, dan Sabiran. Pada tahun enam puluhan dapat pula disebut berberapa seniman mamanda seperti Asmuni, Masauri, Dulmas, Nasran Dalau, Adul Sabra, Sulaiman, Dayat, Asli, Markani, dan Sapri Kadir. Kemudian, pada tahun tujuh puluhan dapat pula disebut berberapa seniman mamanda seperti Burhan, Husni, Kursani, Abdurrasyid, Markabi, dan Sail.

Dalam perkembangannya, seniman mamanda muncul dari beberapa teater seperti pada Teater Banjarmasin, muncul beberapa nama seperti M. Jaini, Abdullah Sp, dan A. Mariyono. Selain itu, khususnya di Banjarbaru, dalam kelompok Mamanda Idaman muncul beberapa nama seperti A. Rivol, Abdul Marwan, Sidik, dan Arifani (Huda, 2012:5).

Sementara itu, dari Hulu Sungai Selatan (HSS), ada beberapa kelompok atau group seniman mamanda yang pernah ada, di antaranya Sampuraga dari Karang Jawa pimpinan Bahrani, Ambang Fajar di Desa Amawang pimpinan Ismail, Tanjung Pusaka (juga di Desa Amawang), Rangganala di Kandangan Hulu dan Kumba di Muara Banta. Selain itu, hampir di seluruh daerah lain di wilayah HSS pernah pula ada komunitas mamanda, seperti Angkinang, Telaga Langsat, Bamban, Riam Tajam, Tabihi, Kaliring Dalam, Ambarai, Jalatang, Tanah Bangkang, Sungai Kudung, Tanayung, Ambutun, Binjai Tiga, dan Parincahan. Group mamanda di HSS yang masih bertahan sampai hari ini adalah Sampuraga dari Karang Jawa.

Masih dari HSS, juga terdapat beberapa nama seniman mamanda yang sangat kesohor, baik yang sudah pensiun atau masih aktif bergelar, di antaranya A. Syarmidin dari Kandangan, Ancah dari Parincahan, dan H Syahrani dari Pisangan. Mereka semasa aktif menggelar mamanda biasanya berlakon sebagai raja. Pambakal Aan asal Karang Jawa, sering berperan sebagai rampok. Asikin asal Karang Jawa membawa lakon seorang perempuan. Juga beberapa nama seperti Ruslan Faridi (alm) asal Tibung Raya, Muliadi (alm) dari Teluk Masjid, Bahtiar (alm) dari Karang Jawa, Hairin Najrin dari Jambu Hlir Baluti, Bahrani dari Karang Jawa, Jafuri Baseri (alm) dari Padang Panjang, Ahmad Riduan dari Gambah Luar, Desi Alisa Pujianti dai Gambah Luar Muka, Abdaludin dari Kandangan, Fakhruddin dari Jambu Hulu Banua Hanyar, Jumberi dari Jalatang, Burhan dari Tabihi Lajar. Beberapa tokoh muda yang juga sering ikut berperan dalam mamanda adalah Rahman Rizani atau Bagan Topeng dari Taniran Kubah, dan Rika Ayu Zainab atau Icha (http://www.kompasiana.com/ husaini.angkinang/kesenian-mamanda-yang-masih-eksisdihss551fc93a81331151019 dfd21).

Selain beberapa nama seniman mamanda yang sudah dikenal di Kalimantan Selatan juga beberapa teater (sanggar) yang juga (pernah) menggelar pertunjukan mamanda, misalnya Teater Air, Teater At-tadib, Teater Demokrat, Teater Himasido, Teater Kereta, Teater Pena, Teater Sesaji, Sanggar Bahana Antasari, dan Sanggar Budaya. 
Dalam perkembangannya, mamanda tidak hanya dapat disaksikan pada pertunjukan secara langsung, tetapi juga dapat disaksikan (ditonton) pada televisi, VCD, bahkan dewasa ini pada media sosial melalui youtobe. Semua itu memperlihatkan bahwa mamanda di Kalimntan Selatan tetap eksis.

Selain itu, dalam rangka pengembangan mamanda juga pernah diadakan lomba mamanda terutama untuk kalangan pelajar dan mahasiswa se-Kalimntan Selatan. Meskipun pada saat lomba tersebut tidak banyak group dari pelajar dan mahasiswa yang mengikuti. Hal tersebut terutama keterbatasan pelajar dan mahasiswa terutama berkenaan dengan sarana bermain yang dimiliki seperti tetabuhan dan kostum. Jika mereka ingin menggelar pertunjukan mamanda, mereka harus menyewa kostum, termasuk tetabuhan dengan penabuhnya sekaligus.

Sementara itu, media cetak juga punya peran dalam rangka pengembangan mamanda di Kalimntan Selatan. Hal tersebut terutama dengan terbitnya beberapa buku yang berkenaan dengan mamanda, seperti Mamanda Ampunlah Tuanku oleh Burhanuddin Soebely (2002), Mamanda: dari Realitas Tradisional ke Kesenian Populer Seni Pertunjukan Banjar oleh Jarkasi (2002), Mamanda Sebuah Teater Eksodus oleh Hermansyah (2007), dan Naskah Pertunjukan Mamanda Teater Tradisi Banjar oleh Sirajul Huda (2012). Bahkan dalam buku Naskah Pertunjukan Mamanda Teater Tradisi Banjar dimuat beberapa naskah mamanda yang ditulis oleh Sirajul Huda. Naskah mamanda tersebut tentu saja sangat membantu apabila ada yang ingin menggelar pertunjukan mamanda.

\section{B. Upaya Pengembangan Mamanda di Kalimantan Selatan \\ 1. Peran Pemerintah}

Dalam rangka mengembangkan mamanda di Kalimantan Selatan, pemerintah tentu saja diharapkan lebih meningkatkan perannya. Peran pemerintah dalam rangka mengembangkan kesenian mamanda dapat dilakukan misalnya dalam rangka peringatan hari-hari besar dapat melaksanakan pertunjukan mamanda. Hari-hari besar tersebut, misalnya pada saat perayaan Hari Ulang Tahun Kemerdekaan Republik Indonesia, Hari Jadi Provinsi Kalimantan Selatan, Hari Jadi Kota, atau Hari Jadi Kabupaten. Begitu pula dengan perayaan hari-hari besar diharapkan melaksanakan pertunjukan mamanda. Juga pada momen-momen tertentu yang dilaksanakan oleh pihak pemerintah.

Misalnya di Hulu Sungai Selatan (HSS) saat ini pagelaran mamanda sudah dijadikan agenda wajib tahunan. Setiap tahun pertunjukan mamanda digelar sebanyak tiga kali, yaitu tanggal $17 \mathrm{Mei}$, pada saat peringatan ALRI Divisi IV, tanggal 17 Agustus, pada saat peringatan Hari Kemerdekaan RI, dan tanggal 2 Desember, pada saat peringatan Hari Jadi Kabupaten Hulu Sungai Selatan (http://www.kompasiana.com/husaini.angkinang/kesenian-mamanda-yang-masiheksis-di-hss_551fc93a81331151019dfd21).

Beberapa sarana yang berkenaan dengan pemerintah sebaiknya juga terus mendukung pertunjukan mamanda, misalnya Taman Budaya, Dinas Pariwisata, maupun TVRI. Selain dukungan dari beberapa sarana tersebut dalam pertunujukan mamanda, beberapa sarana tersebut sebaiknya melaksanakan (kembali) lomba mamanda baik tingkat pelajar, mahasiswa, maupun umum. Dengan demikian mamanda akan semakin eksis pada setiap lapisan masyarakat dan akan semakin berkembang dari waktu ke waktu. 


\section{Peran Lembaga Pendidikan}

Dalam rangka mengembangkan mamanda, lembaga pendidikan tentu saja juga diharapkan punya peran. Peran lembaga pendidikan dalam rangka mengembangkan mamanda dapat dilakukan misalnya menjadikan mamanda sebagai salah satu kesenian yang harus dipelajari di sekolah-sekolah sebagaimana layaknya beberapa kesenian lainnya. Pembelajaran tersebut dapat dilakukan misalnya pada mata pelajaran kesenian. Bisa pula misalnya pada kegiatan ekstrakurikuler. Baik pada tingkat sekolah dasar, tingkat sekolah menengah pertama, maupun tingkat sekolah menengah atas.

Hal yang juga tidak kalah penting dalam rangka mengembangkan mamanda di sekolah-sekolah yaitu penyediaan sarana untuk pertunjukan mamanda, terutama kostum dan tetabuhan. Ketiadaan sarana semacam itu tentu saja akan dapat menghambat pembelajaran mamanda di sekolah-sekolah. Meskipun sekolah dapat misalnya menyewa untuk kostum dan tetabuhan, tetapi hal tersebut tentu kurang efesien.

Begitu pula pada perguruan tinggi, sudah seharusnya perguruan tinggi terus mendukung para mahasiswa yang memang sudah eksis pada mamanda. Hal tersebut dapat dilihat pada beberapa teater yang ada di perguruan tinggi yang juga menggelar pertunjukan mamanda.

Selain itu, pihak sekolah dapat pula mengundang pelakon atau seniman mamanda untuk pembekalan materi bagi pelajar dalam rangka pengenalan mamanda. Bahkan dapat pula pelakon atau seniman mamanda tersebut melatih para pelajar andaikata menggelar pertunujukan mamanda pada (beberapa) acara yang digelar di sekolah masing-masing. Begitu pula tentunya bagi perguruan tinggi. Bahkan pada perguruan tinggi yang terkait, dapat mengundang pelakon atau seniman mamanda sebagai dosen tamu dalam rangka pembelajaran mamanda bagi mahasiswa.

\section{Peran Seniman}

Dalam rangka mengembangkan mamanda, seniman tentu saja diharapkan semakin meningkatkan perannya. Peran seniman dalam rangka mengembangkan mamanda di Kalimantan Selatan, selain sebagai pelakon mamanda, diharapkan juga mengembangkan ilmunya pada generasi yang kemudian, misalnya melalui pelatihan maupun workshop mengenai mamanda. Dengan demikian, seniman mamanda di Kalimnatan Selatan akan semakin berkesinabungan. Meskipun, sebagaimana dikemukakan sebelumnya, bahkan sejak tahun lima puluhan hingga sekarang, seniman mamanda terus eksis.

Hal yang juga tidak kalah penting diperhatikan bagi seniman mamanda, yaitu terus mengembangkan mamanda dengan berbagai variasi agar semakin diminati oleh masyarakat (penonton). Sebagaimana yang selama ini sudah dilakukan seperti mengembangkan kisahan (cerita) yang semakin terkait dengan kehidupan masyarakat (penonton). Juga adanya humor yang semakin memikat penonton. Dengan demikian kisahan mamanda tidak hanya mengulang kisahan yang ada, selama kisahan itu tidak melanggar pakem yang ada. 


\section{Peran Masyarakat}

Dalam rangka mengembangkan mamanda, masyarakat tentu saja juga diharapkan punya peran. Peran masyarakat dalam rangka mengembangkan mamanda dapat dilakukan misalnya menjadi penonton aktif. Sementara itu, pihak seniman mamanda juga harus memperhatikan segmen penonton mamanda. Pada umumnya segmen penonton mamanda di Kalimantan Selatan terutama kalangan masyarakat lapisan bawah seperti pelajar, mahasiswa, ibu-ibu, nenek-nenek, juga kakek-kakek. Masyarakat terutama menyukai kisahan yang terkait dengan kehidupan, terutama dengan kenyataan hidup yang mereka alami dewasa ini.

Tambatan masyarakat terhadap pertunjukan mamanda terutama karena mamanda disajikan dengan garapan yang mendasarkan diri pada musik rakyat, nyayian rakyat, tarian rakyat, dan kisahan yang benar-benar terkait dengan kehidupan rakyat dewasa ini. Lebih-lebih diselengi dengan humor (cerdas) yang semakin memikat penonton.

\section{SIMPULAN}

Sejauh yang dapat dicatat, mamanda di Kalimantan Selatan sudah eksis sejak tahun lima puluhan, enam puluhan, tujuh puluhan, hingga sekarang. Hal tersebut dapat diketahui dari munculnya berberapa nama seniman mamanda. Dalam perkembangannya, sekarang seniman mamanda juga muncul dari beberapa teater (sanggar). Ada pula dari beberapa kelompok atau group seniman mamanda. Dalam perkembangannya, mamanda tidak hanya dapat disaksikan pada pertunjukan secara langsung, tetapi juga dapat disaksikan (ditonton) pada televisi, VCD, bahkan dewasa ini pada media sosial melalui youtobe. Semua itu memperlihatkan bahwa mamanda di Kalimntan Selatan tetap eksis.

Dalam rangka mengembangkan mamanda di Kalimnatan Selatan, agar mamanda semakin eksis, diharapkan adanya peran dari beberapa pihak, baik yang berkaitan dengan pemerintah, lembaga pendidikan, seniman, maupun masyarakat. Peran pemerintah, misalnya dalam rangka peringatan hari-hari besar dapat melaksanakan pertunjukan mamanda. Peran lembaga pendidikan, misalnya menjadikan mamanda sebagai salah satu kesenian yang harus dipelajari terutama di sekolah-sekolah. Peran seniman, selain sebagai pelakon mamanda, diharapkan juga dapat mengembangkan ilmunya pada generasi yang lebih kemudian. Peran masyarakat, misalnya menjadi penonton pertunjukan mamanda secara aktif.

\section{DAFTAR PUSTAKA}

Asmuni, Fahrurraji. 2012. Sastra Lisan Banjar Hulu: untuk Pelajar dan Umum. Banjarbaru: Penerbit Penakita.

Hermansyah. 2007. Mamanda Sebuah Teater Eksodus. Yogyakarta: BKPBM dan Adicita

Huda, Sirajul. 2012. Naskah Pertunjukan Mamanda Teater Tradisi Banjar. Banjarbaru: Penerbit Scripta Cendekia.

Jarkasi. 2002. Mamanda: dari Realitas Tradisional ke Kesenian Populer Seni Pertunjukan Banjar. Banjarmasin: Penerbitan PT Grafika Wangi.

Soebely, Burhanuddin. 2002. Mamanda Ampunlah Tuanku. Kandangan: Penerbit Dinas Pariwisata dan Kebudayaan Kabupaten Hulu Sungai Selatan. 
Sunarti, dkk. 1978. Sastra Lisan Banjar. Jakarta: Pusat Pembinaan dan Pengembangan Bahasa Departemen Pendidikan dan Kebudayaan.

http://www.kompasiana.com/husaini.angkinang/kesenian-mamanda-yang-masiheksis-di hss 551fc93a81331151019dfd21, "Kesenian Mamanda yang Masih Eksis di HSS”, Akhmad Husaini, diakses, 13 Desember 2015.

https://www.google.com/search?q=teater+rakyat+mamanda\&sa=X\&biw=1366\&b ih=631\&tbm=isch\&imgil=t2scekrZozZD_M\%253A\%253BciD4b7MaY4h b3M\%253Bhttp\%25253A\%25252F\%25252Fbudayaindonesia.org\%25252 FMamanda\%25252F\&source=iu\&pf=m\&fir=t2scekrZozZD_M\%253A\%2 52CciD4b7MaY4hb3M\%252C_\&usg=_Gbsdpqiq3yemLC0I42_kemZTx 1M\%3D\&ved=0ahUKEwiE2oXf_djJAhUGW5QKHQv5AkQQyjcIOg\&ei $=$ HdtVoTNYa20QSL8ougBA\#imgrc=OApR2HkLF2IGuM\%3A\&usg=Gb sdpqiq3yemLC0I42_kemZTx1M\%3D, diakses, 13 Desember 2015. 